
\title{
(s)
}

\section{Effect of Post Heated TiN Coating on Pitting Corrosion of Austenitic Stainless Steel}

\author{
Cheng-Hsun Hsu*, Hong-Tsair Liu, Wei-Che Huang and Meng-Ru Lin \\ Department of Materials Engineering, Tatung University, Taipei 104, Taiwan
}

\begin{abstract}
This study used cathodic arc deposition technique to coat TiN film on 316L austenitic stainless steel, and then the coated specimens were heat-treated at the different temperatures. Observation of coating morphology and corrosion tests were conducted for exploring the effect of post-heating temperature on composition, microstructure, and corrosion behavior of the coatings. The results showed when the heating temperature was up to the range of $500-600{ }^{\circ} \mathrm{C}$, a Ti-N-O mixed film consisting of the two $\mathrm{TiO}_{2}$ and TiN phases was formed on the outer layer. Particular, the film heated at $500{ }^{\circ} \mathrm{C}$ had a dense structure as well as homogeneous chemical composition. Such the result could effectively inhibit pitting corrosion of $316 \mathrm{~L}$ stainless steel in $3.5 \mathrm{wt} \% \mathrm{NaCl}$ and $10 \mathrm{vol} \% \mathrm{HCl}$ solutions.
\end{abstract}

Received on 04-11-2015

Accepted on 08-12-2015

Published on 05-01-2016

Keywords: Cathodic arc deposition, TiN film, 316L stainless steel, Post-heating, Pitting corrosion.

\section{INTRODUCTION}

It is well known that stainless steels process well corrosion resistance, oxidation resistance and formability, particular austenitic stainless steels, which have been widely used in various engineering applications and high quality goods, such as surgery instruments, artificial joints, and precision watches [1]. Despite these advantages, however, the steels still have some shortcomings, such as low hardness and pitting corrosion in chlorine environment [2-5]. Physical vapor deposition (PVD) technology has become a popular method of surface treatment for several decades, because this method allows at low processing temperatures to deposit ceramic coatings on metallic substrates [6]. For example, various nitride films such as TiN, CrN, ZrN, TiAIN, and their combination could be successfully coated on austenitic stainless steels by PVD method to enhance surface property [7-11]. In particular, titanium nitride (TiN) not only has an intrinsic golden color, but also exhibits high hardness, good thermal and electrical conductivity. Such the attractive properties, thus TiN becomes an important film material in engineering applications [12]. Furthermore, some researchers utilized oxygen addition to form $\mathrm{Ti}-\mathrm{N}-\mathrm{O}$ film by sputtering for varying $\mathrm{TiN}$ coating color, structure and hardness. Impressively, color altered from golden type to dark blue with an increase of oxygen addition in the Ti-N-O coatings [13, 14]. A past study [15] also used cathodic arc deposition (CAD) system varying $\mathrm{O}_{2} / \mathrm{N}_{2}$ ratio of reactive

"Department of Materials Engineering, Tatung University, Taipei 104, Taiwan; Tel: (886-2)-2586-6410; E-mail: chhsu@ttu.edu.tw gases to synthesize Ti-N-O coatings. The result showed when the $\mathrm{O}_{2} / \mathrm{N}_{2}$ ratio was controlled at 0.25 , a dense Ti-N-O film was obtained to effectively increase the wear resistance of AISI 304 stainless steel. Another previous study [16], TiN films after annealing to form Ti-N-O phase could also improve tribological property of austenitic stainless steel. According to the experimental result, we are interested to continue explore the effect of $\mathrm{Ti}-\mathrm{N}-\mathrm{O}$ film on pitting corrosion of austenitic stainless steel.

Thereby, the purpose in the study is to coat TiN films on austenitic stainless steel by CAD method along with post heat treatment at different temperatures. Coating structure, composition, roughness, and adhesion were all analyzed. In addition, the corrosion tests were carried out to evaluate the effect of post-heating temperature on the corrosion behavior of the coated specimens.

\section{EXPERIMENTAL PROCEDURES}

In this study, AISI 316L stainless steel was adopted as the experimental material and machined as the substrates with a diameter of $15 \mathrm{~mm} \times 15 \mathrm{~mm} \times 5 \mathrm{~mm}$ in size. Prior to deposition, the substrates were polished, degreased, ultrasonically cleaned, rinsed with alcohol, and dried by warm air. The base vacuum was approximately $9 \times 10^{-3} \mathrm{~Pa}$. The bombardments of argon ion at the bias of $-700 \mathrm{~V}$ for 10 min were carried out to further ensure good adhesion of the deposited films. Two opposite titanium targets (99.99\% purity) were mounted at the both sides of the chamber, while the reactive gas of $\mathrm{N}_{2}$ was used to deposit TiN film. Before TiN coating, a pure Ti- 
interlayer was deposited for enhancing the adhesion between TiN and substrate. The distance between the target and substrate was $150 \mathrm{~mm}$. The other deposition parameters were also selected as follows: the $\mathrm{N}_{2}$ flow rate $=50 \mathrm{sccm}$, the substrate bias voltage $=-150 \mathrm{~V}$, the evaporation current $=60$ $\mathrm{A}$, the substrate temperature $=270{ }^{\circ} \mathrm{C}$, the holder rotation rate $=4 \mathrm{rpm}$, and depositing time $=40 \mathrm{~min}$. After coating, post heat treatments of the TiN-coated specimens were separately carried out at 400,500 , and $600{ }^{\circ} \mathrm{C}$ for 2 hours in an air furnace. According to the three temperatures, the heated TiN coatings in this paper were marked as TiN(400), TiN(500), and TiN(600), respectively.

A field emission scanning electron microscopy (FESEM, LEO 1530) was used at an accelerating voltage of $15 \mathrm{kV}$ to observe the coating morphology and to measure the coating thickness. A glancing incidence X-ray diffractormeter (XRD, Rigaku- TTTRAX III) was employed to identify the coating structure with a Cu-target $\mathrm{K} \alpha$ radiation at $40 \mathrm{kV}$ and $30 \mathrm{~mA}$ and a glancing incident angle of $2^{\circ}$; the scanning angular (20) ranged from $20^{\circ}$ to $80^{\circ}$ at $2^{\circ} / \mathrm{min}$. The chemical composition of the films was determined by the quantitative electron probe microanalysis (EPMA, JEOL JXA-8200) with the mode of line scanning for $\mathrm{Ti}, \mathrm{N}$, and $\mathrm{O}$ elements. A surface roughness analyzer (Mitutoyo SV-400) was applied to measure the average surface roughness (Ra value) for each specimen. Adhesion strength quality (ASQ) of the coatings was evaluated by using Rockwell-C indentation testing with a load of $1471 \mathrm{~N}$ [17]. The damage to the coatings was compared
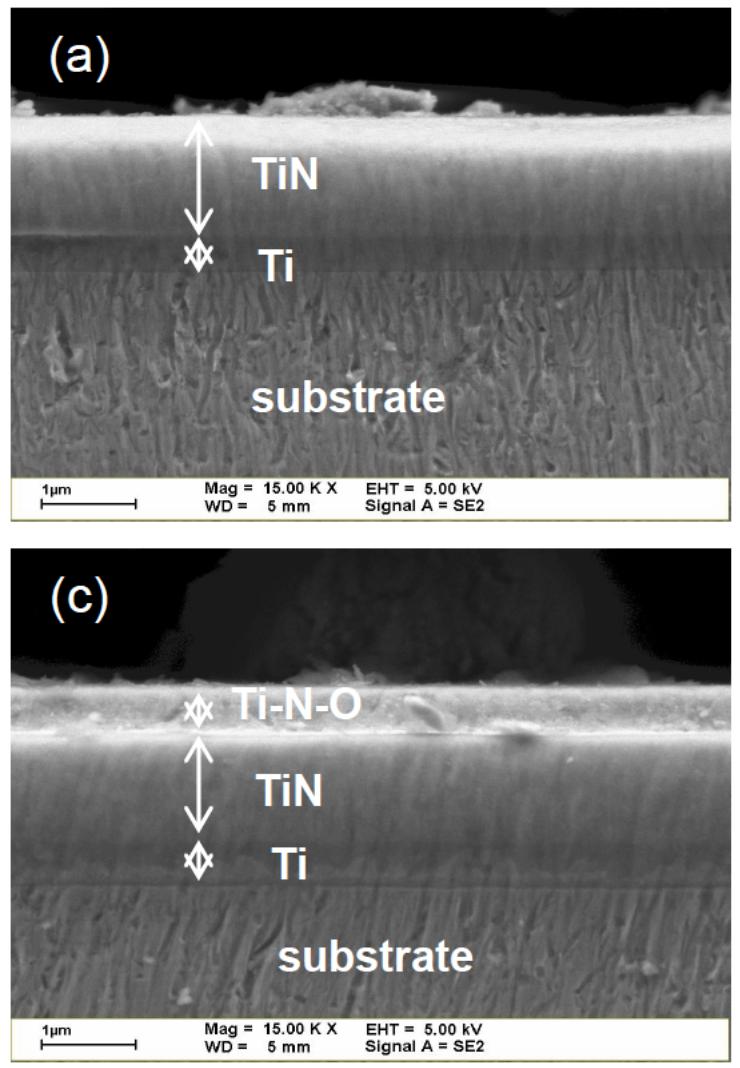

with a defined ASQ basis, where the grades of HF1-HF4 were acceptable adhesion and HF5-HF6 represented insufficient adhesion (HF is the German short form for adhesion strength).

In addition, corrosive experiments were conducted in the air and divided two types: polarization test and immersion test. Moreover, the two corrosive media of $3.5 \mathrm{wt} . \% \mathrm{NaCl}$ and 10 vol.\% $\mathrm{HCl}$ solutions were selected for simulating the aggressive aqueous environment containing $\mathrm{Cl}^{-}$ions. In the case of polarization tests, a potentiostat/galvanostat apparatus (EG\&G model 263A, USA) was used to conduct corrosion tests and the $3.5 \mathrm{wt} . \% \mathrm{NaCl}$ solution was selected as medium to simulate the sea water environment. A standard saturated calomel electrode (SCE) was used as a reference and platinum as a counter- or auxiliary electrode. The contact area in all cases was $1 \mathrm{~cm}^{2}$, and the tests were carried out at ambient temperature. The electrode potential was raised from $-0.5 \mathrm{~V}$ to $0.3 \mathrm{~V}$ at a scanning rate of $1 \mathrm{mV} / \mathrm{s}$. All polarization curves were obtained after $30 \mathrm{~min}$ of free immersion of the specimens in order to stabilize the open circuit potential (OCP). Corrosion potential $\left(E_{\text {corr. }}\right)$ and corrosion current density $\left(I_{\text {corr. }}\right)$ values were further obtained by the polarization curve and the Tafel extrapolation method, respectively [18-20]. The percentage inhibition efficiency $\left(\psi_{\mathrm{pol}} \%\right)$ was calculated using the $I_{\text {corr. }}$ values to express the relation $\psi_{\mathrm{pol}} \%=\left[\left(I_{\text {corr }}-I_{\text {corr }}\right) / I_{\text {corr }}\right] \times 100$, where both $I_{\text {corr }}$ and $l_{\text {corr }}$ are uninhibited and inhibited corrosion current densities, respectively $[19,20]$. All the polarization tests were carefully
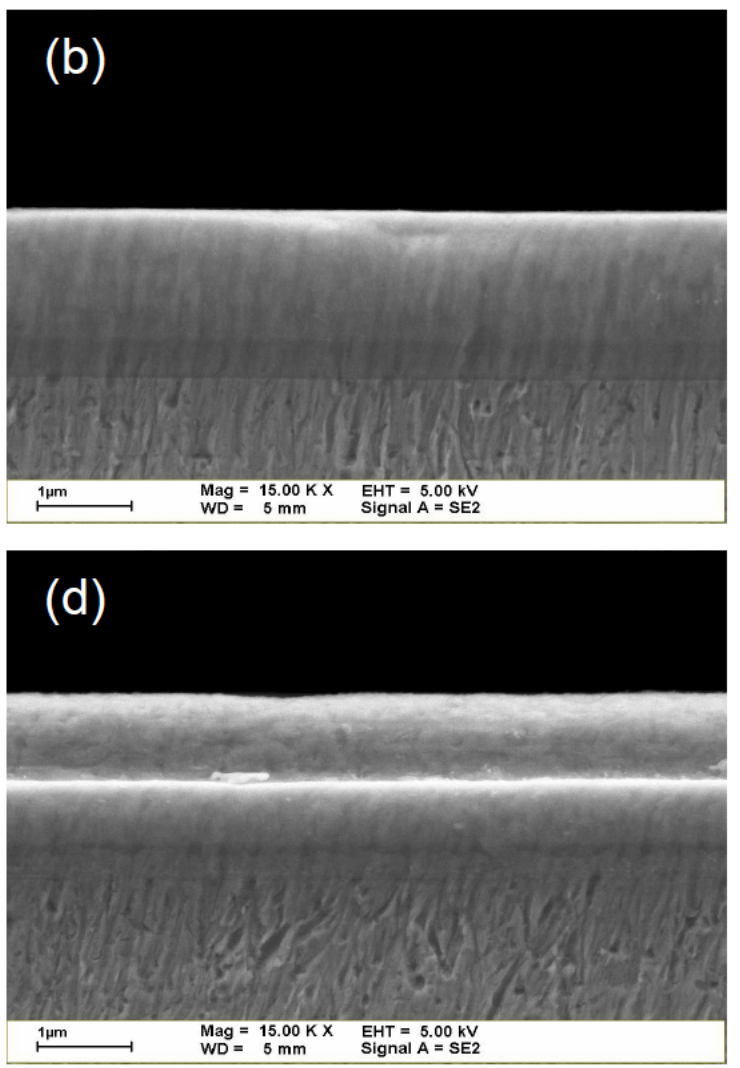

Figure 1: SEM Cross-sectional view of the coated specimens: (a) TiN, (b) $\operatorname{TiN}(400),(\mathbf{c}) \operatorname{TiN}(500)$, and (d) $\operatorname{TiN}(600)$. 
carried out to avoid any scratch in the coatings. In the case of immersion tests, all the specimens were cleaned by using ultrasonic cleaning with alcohol before respectively immersed in 10 vol.\% hydrochloric acid at room temperature. The weight loss was measured by using a micro-balance $\left( \pm 1 \times 10^{-4}\right.$ g) at various time intervals. Also, the corroded surface of each specimen after corrosion tests was observed using SEM.

\section{RESULTS AND DISCUSSION}

\subsection{Coating Structure and Composition}

The study used FESEM to observe cross-sectional view of the TiN-coated specimens before and after post-heating treatment, as shown in Figure 1. From Figure 1a, it is observed that the coating had a columnar morphology, consisting of about $1.4 \mu \mathrm{m}$ TiN film and $0.4 \mu \mathrm{m}$ Ti-interlayer. After post-heating of $400{ }^{\circ} \mathrm{C}$ for $2 \mathrm{~h}$, the TiN film almost had no variation in morphology (Figure $\mathbf{1 b}$ ). It implied that the TiN film presented the well oxidation resistance at $400{ }^{\circ} \mathrm{C}$. When the post-heating temperature was up to $500-600{ }^{\circ} \mathrm{C}$, it was noted that a dense thin film of about $0.5-0.9 \mu \mathrm{m}$ formed on the outward of the TiN-coated specimens. Moreover, the outer-layer in thickness had an increase while the thickness of original TiN film lessened with raising post-heating temperature, as shown in Figures $\mathbf{1 c}$ and d. Figure 2 compares the crystal structures of the coatings with and without post-heating in terms of the XRD patterns. The result showed that the un-annealed film had the main peaks on (111), (200), (220), and (311) diffracting planes for the TiN film because the depositing reaction between nitrogen and titanium ions formed a NaCl-type structure [21]. The XRD pattern of $\mathrm{TiN}(400)$ was almost the same with the unannealed one. For the $\mathrm{TiN}(500)$ and $\mathrm{TiN}(600)$ films, there were some peaks of rutile- $\mathrm{TiO}_{2}$ crystalline plane occurring in the XRD pattern besides the TiN peaks. Such the result

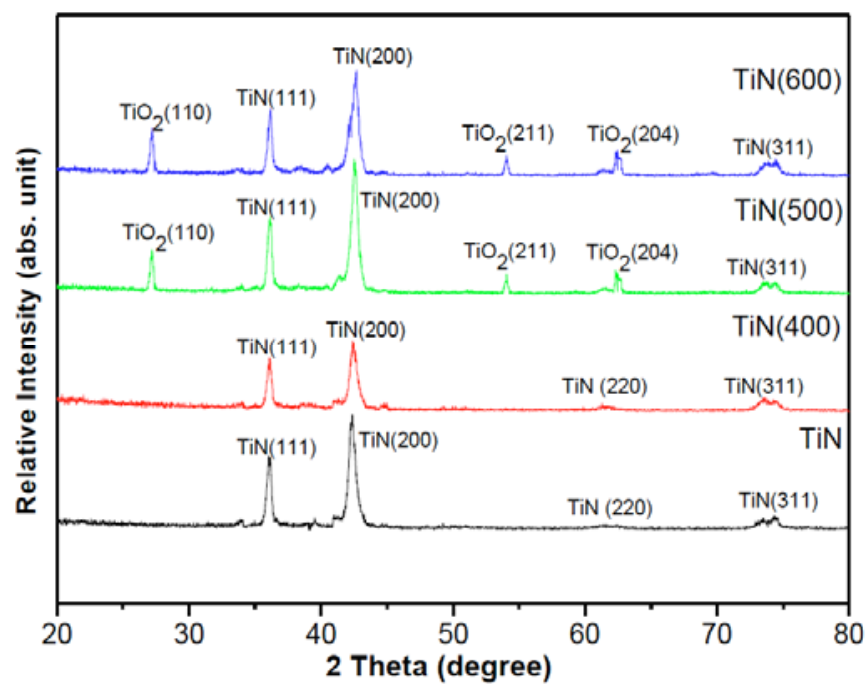

Figure 2: XRD patterns of the TiN coated specimens before and after annealing. inferred that the outer-layer formed on the $\mathrm{TiN}(500)$ and $\mathrm{TiN}(600)$ specimens should be a Ti-N-O film, consisting of the rutile- $\mathrm{TiO}_{2}$ and $\mathrm{TiN}$ phases. Moreover, the $\mathrm{TiO}_{2}$ peaks in $\operatorname{TiN}(600)$ seemed to be stronger than that in $\operatorname{TiN}(500)$ due to the former with a thicker out-layer as compared to the latter (0.9 vs. $0.5 \mu \mathrm{m})$.

Chemical compositions of un-annealed and annealed coatings analyzed by EPMA are compared in Figure 3. For un-heated and heated at $400{ }^{\circ} \mathrm{C}$ conditions, both the coated specimens almost had the same contents for Ti (51.4 vs. 51.6 at.\%) and $\mathrm{N}$ (48.6 vs. 48.4 at.\%) elements in its Ti-N binary film. The result indicated that TiN film had the stable oxidation resistance under the post-heating temperature of $400{ }^{\circ} \mathrm{C}$. When the coated specimen was heated at $500{ }^{\circ} \mathrm{C}$, the oxygen content in the film was slightly higher than that of nitrogen (33.1 vs. 29.7 at.\%). To further raise the postheating temperature up to $600{ }^{\circ} \mathrm{C}$, the oxygen content in the film greatly increased (53.6 at.\%) while both the nitrogen content (12.2 at.\%) and the titanium content (34.2 at.\%) decreased substantially. The result denoted that some of the nitrogen atoms were substituted by oxygen atoms to form $\mathrm{TiO}_{2}$ in Ti-N-O outer-layer. That is, the affinity of titanium and oxygen is stronger than that of titanium and nitrogen [15]. We found, thickness and composition of the outer-layer depended on post-heating temperature. It is noticed that the Ti-N-O outer-layer in $\mathrm{TiN}(500)$ was thinner but more uniform than that in $\operatorname{TiN}(600)$ due to with the close content in $\mathrm{Ti}, \mathrm{N}$, and $\mathrm{O}$ elements.

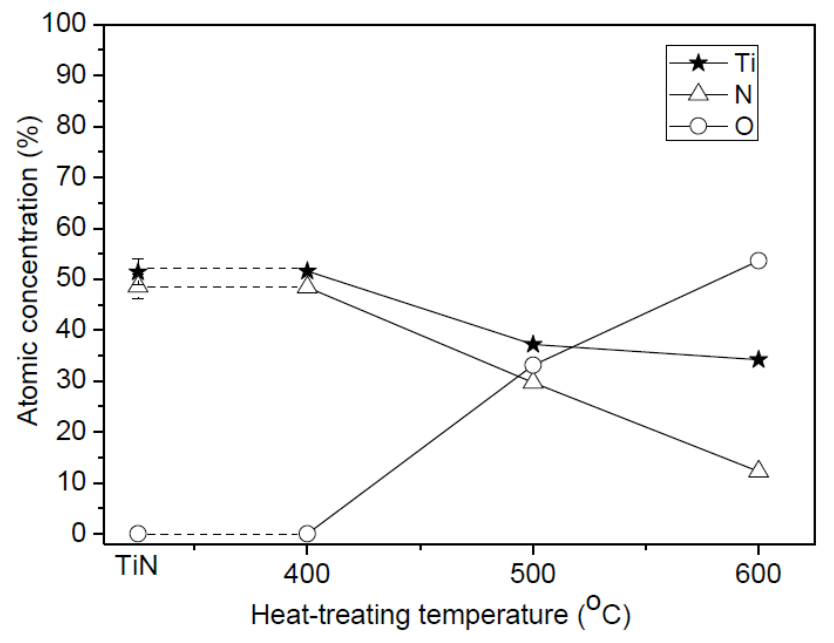

Figure 3: Effect of annealing temperature on the averaged concentration of the $\mathrm{Ti}, \mathrm{N}$, and $\mathrm{O}$ elements in the coating.

\subsection{Analysis of Coating Roughness and Adhesion}

In terms of surface roughness, the TiN coated specimen had a rougher surface than the uncoated one (Ra: 0.22 vs. 0.05 $\mu \mathrm{m})$. The main reason for this phenomenon could be attributed to macro-particles deposited on the substrate by CAD process [22]. After post-heating, the surface roughness of TiN film had a slight decrease at $500{ }^{\circ} \mathrm{C}$ (Ra: $0.20 \mu \mathrm{m}$ ) but increased at $600{ }^{\circ} \mathrm{C}$ (Ra: $\left.0.33 \mu \mathrm{m}\right)$. The result should be 

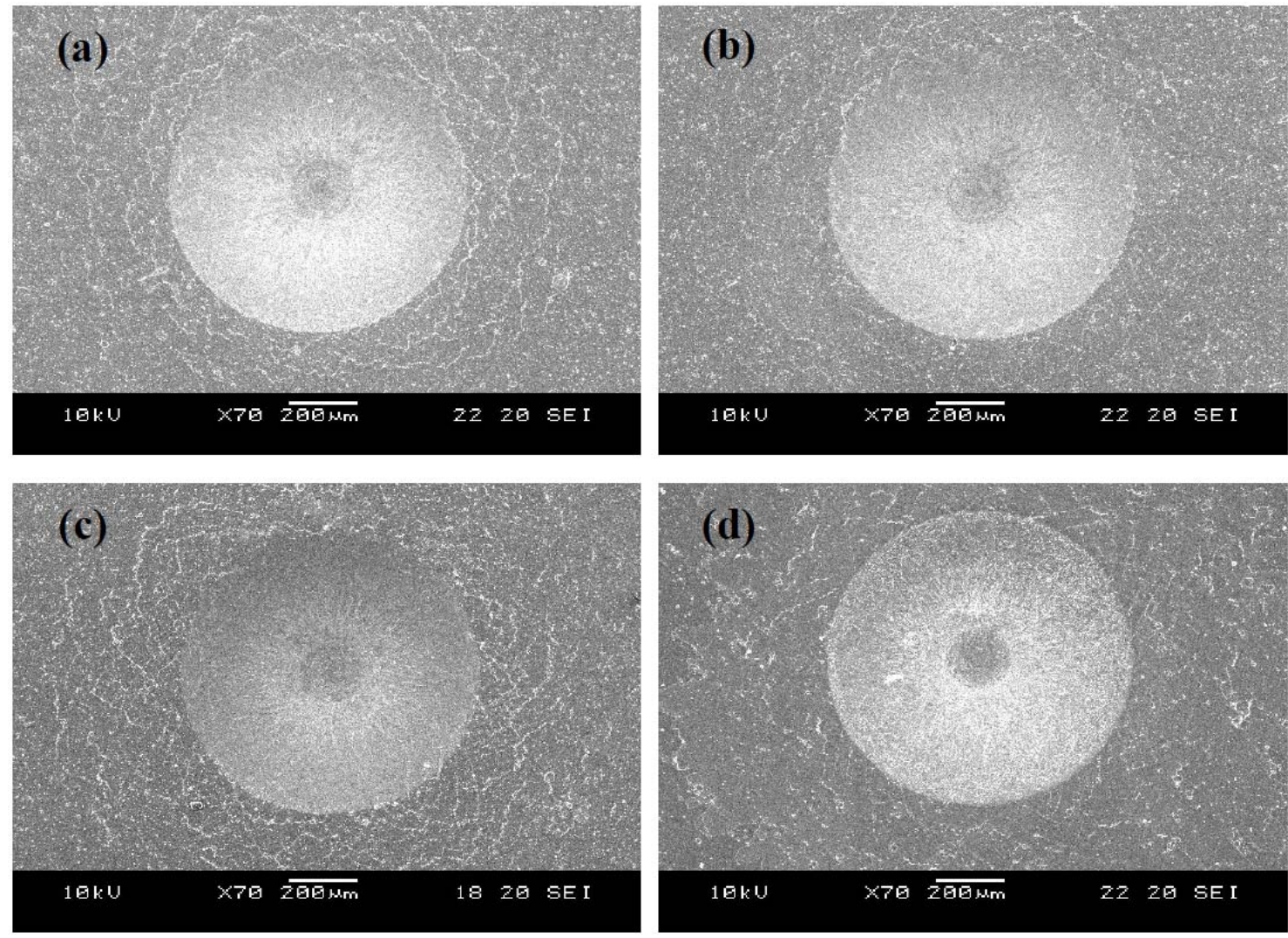

Figure 4: Fracture morphology of the coated specimens by Rockwell-C hardness tester: (a) TiN, (b) TiN(400), (c) TiN (500), and (d) TiN(600).

dependent upon atomic distribution in the Ti-N-O outer-layer. That is, the film with the more uniform composition tends to the lower $\mathrm{Ra}$ value. Indentation tests were performed by using the Rockwell-C hardness tests to evaluate the coating adhesion between film and substrate. According to the definition of ASQ as aforementioned [17], we found that all the TiN coated specimens had a clear and smooth indentation regardless of post-heating treatment, closely resembled HF1-HF2 grade (Figure 4). Accordingly, the postheating for TiN film in this study seems to have no influence on the coating adhesion.

\subsection{Analysis of Corrosion Behavior}

Polarization tests for the uncoated $316 \mathrm{~L}$ stainless steel, unheated TiN film, and the three heated films ( $\operatorname{TiN}(400)$, $\mathrm{TiN}(500)$, and $\mathrm{TiN}(600)$ ) were separately performed in 3.5 wt. $\% \mathrm{NaCl}$ solution as aforementioned. Figure $\mathbf{5}$ shows the polarization curves ( $I_{\text {corr. }}$ vs. $E_{\text {corr. }}$ ) of these specimens after polarization tests, and all the data of polarization measurement obtained are listed in Table 1. Comparing to the uncoated substrate, the TiN coated specimens exhibited an increase in $E_{\text {corr }}\left(-0.242\right.$ vs. $\left.-0.196 \mathrm{~V}_{\mathrm{SCE}}\right)$. Further, it was found that the TiN film after post-heating could increase the $E_{c o r r}$ value. Such the result implied that a steadier electrode potential was achieved and indicated an improvement on the corrosion resistance of $316 \mathrm{~L}$ stainless steel via the coating and post-heating treatments. Particularly, $\operatorname{TiN}(500)$ had the highest $E_{\text {corr }}$ value $\left(-0.121 \mathrm{~V}_{\mathrm{SCE}}\right)$ among the coated specimens. Corrosion current density $\left(I_{\text {corr. }}\right)$ was also calculated by using the Tafel equation [18], with a lower value reflecting better corrosion resistance. The result showed that the coated specimens had an evident improvement in corrosion resistance as compared to the uncoated one

Table 1: Data of Polarization Measurement for all the Specimens in this Study

\begin{tabular}{|c|c|c|c|}
\hline Specimen & $\begin{array}{c}\text { Electrode Potential, } \\
\mathrm{E}_{\text {corr. }}\left(\mathbf{V}_{\text {scE }}\right.\end{array}$ & $\begin{array}{c}\text { Corrosion Current Density, } \\
\mathrm{I}_{\text {corr. }}\left(\times \mathbf{1 0} \mathbf{0}^{-\mathbf{A}} \mathbf{\mathbf { c m } ^ { 2 }}\right)\end{array}$ & $\begin{array}{c}\text { Inhibition Efficiency } \\
\boldsymbol{\psi}_{\text {pol }}(\%)\end{array}$ \\
\hline \hline Uncoated 316L & $-0.242 \pm 0.012$ & $22.4 \pm 1.1$ & 12.9 \\
\hline Un-heated TiN & $-0.196 \pm 0.009$ & $19.5 \pm 0.1$ & 54.9 \\
\hline $\operatorname{TiN}(400)$ & $-0.139 \pm 0.007$ & $10.1 \pm 0.5$ & 69.6 \\
\hline $\operatorname{TiN}(500)$ & $-0.121 \pm 0.006$ & $6.8 \pm 0.3$ & 67.8 \\
\hline $\operatorname{TiN}(600)$ & $-0.126 \pm 0.006$ & $7.2 \pm 0.4$ & \\
\hline
\end{tabular}




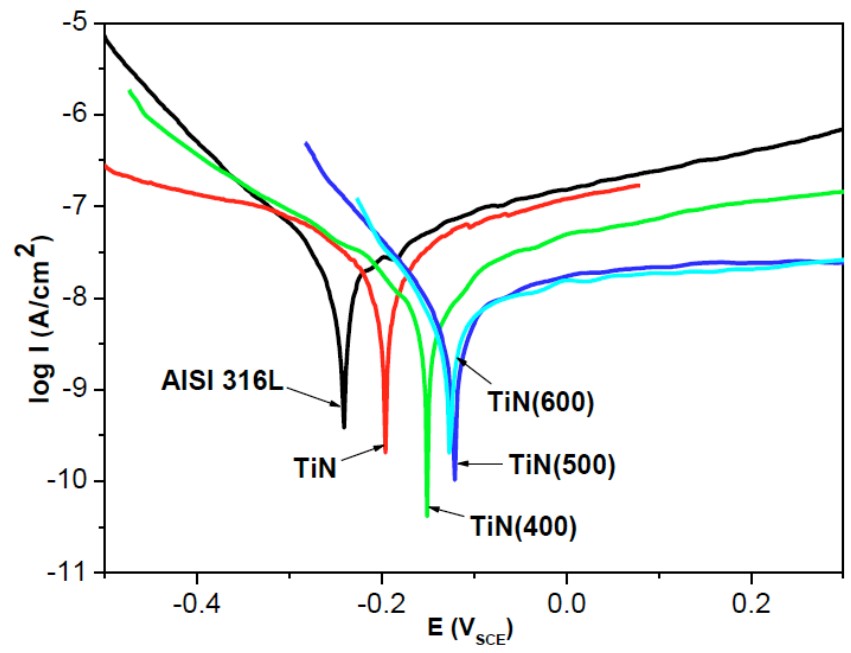

Figure 5: Polarization curves of the coated and uncoated specimens in 3.5 wt. \% $\mathrm{NaCl}$ solution.

$\left(22.4 \times 10^{-9} \mathrm{~A} / \mathrm{cm}^{2}\right)$, where the $I_{\text {corr. }}$ values obtained for $\mathrm{TiN}$, $\mathrm{TiN}(400), \operatorname{TiN}(500)$, and $\mathrm{TiN}(600)$ were $19.5 \times 10^{-9} \mathrm{~A} / \mathrm{cm}^{2}$,
$10.1 \times 10^{-9} \mathrm{~A} / \mathrm{cm}^{2}, \quad 6.8 \times 10^{-9} \mathrm{~A} / \mathrm{cm}^{2}$, and $7.2 \times 10^{-9} \mathrm{~A} / \mathrm{cm}^{2}$, respectively. It is noted that $\mathrm{TiN}(500)$ had the lowest value to indicate the best corrosion resistance. Further, the inhibition efficiencies of corrosion for these coated specimens are listed in Table 1. It can be found that $\operatorname{TiN}(500)$ had the highest value up to $69.6 \%$, followed by $\mathrm{TiN}(600)$, $\mathrm{TiN}(400)$, and finally TiN. Consequently, the corrosion resistance of them is in the order as follows: $\operatorname{TiN}(500)>\operatorname{TiN}(600)>\operatorname{TiN}(400)>\operatorname{TiN}>316 \mathrm{~L}$. Figure 6 shows SEM micrographs of the specimens after the polarization test in $3.5 \mathrm{wt} . \% \mathrm{NaCl}$ solution. For the uncoated $316 \mathrm{~L}$ stainless steel (Figure 6a), we can see a typical morphology of localized corrosion occurred on the surface but without pitting phenomenon. In the case of coated specimens with and without post-heating, the localized corrosion almost disappeared (Figures 6b-e). The result could verify that all the coated specimens had an improvement on corrosion protection as compared to the uncoated one.

Figure 7 shows weight loss of the uncoated and coated specimens with and without post-heating immersed in 10
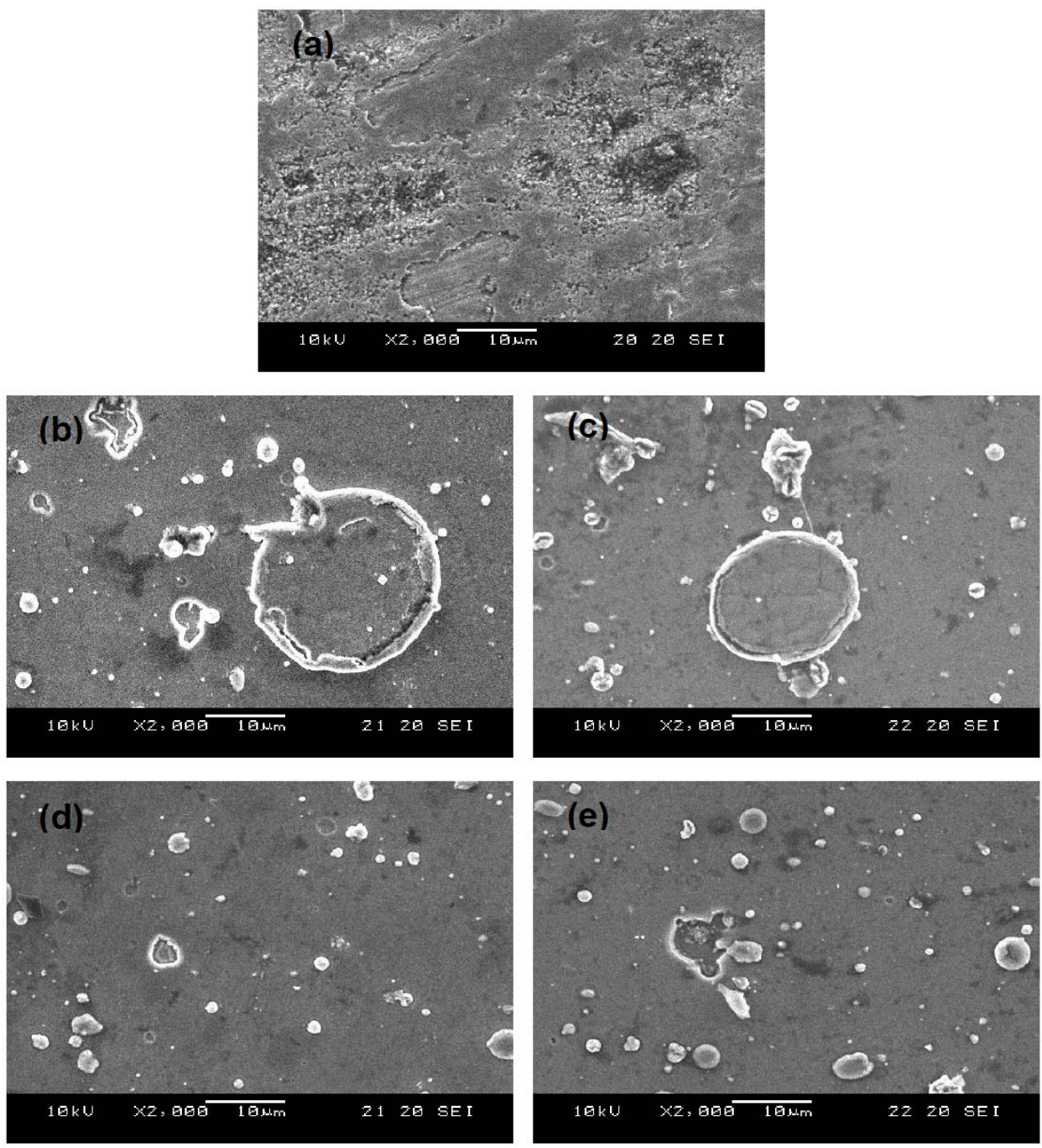

Figure 6: Surface morphology of the coated and uncoated specimens after polarization tests in $3.5 \mathrm{wt} . \% \mathrm{NaCl}$ solution: (a) uncoated, (b) TiN, (c) $\operatorname{TiN}(400)$, (d) TiN (500), and (e) TiN(600). 


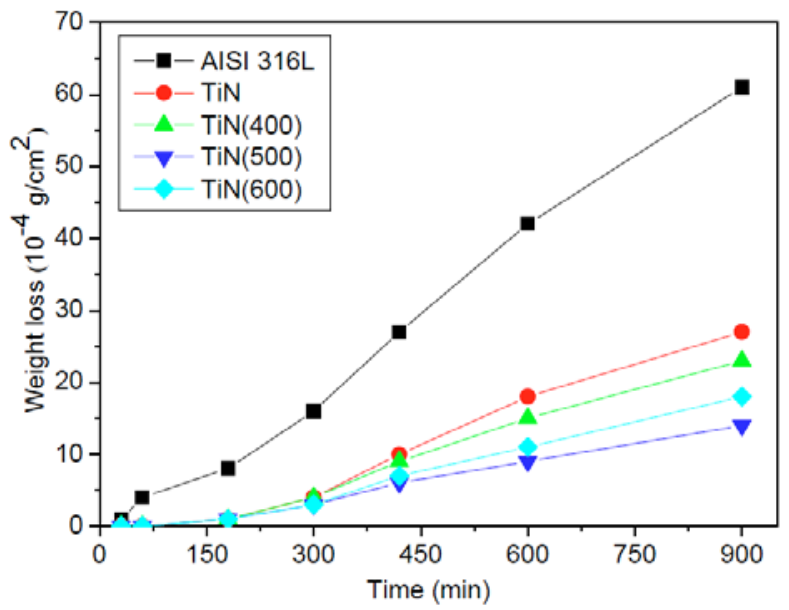

Figure 7: Comparison of weight loss of the various specimens in 10 vol. \% $\mathrm{HCl}$ solution.

vol. $\% \mathrm{HCl}$ solution at room temperature. We can see that the uncoated $316 \mathrm{~L}$ stainless steel had a sharp weight loss because the reactions, $\mathrm{Fe} \rightarrow \mathrm{Fe}^{+2}+2 \mathrm{e}^{-1}$ and $2 \mathrm{H}^{+}+2 \mathrm{e}^{-1} \rightarrow \mathrm{H}_{2}$, took place rapidly in acid medium. In contrast, the coated specimens regardless of post-heating had well protective performance in corrosion resistance. In particular, the TiN(500) specimen efficiently mitigated the weight loss. Figure 8 further shows their SEM micrographs to prove the effect of the coatings on pitting corrosion of $316 \mathrm{~L}$ stainless steel. It can be observed that the uncoated specimen after 900 min immersion tests in $10 \mathrm{vol} . \% \mathrm{HCl}$ solution showed serious pitting corrosion (Figure 8a). After TiN coating and post-heating, the pitting phenomenon was eased up (Figures $8 b-e)$. Particularly, the TiN (500) specimen nearly had no pitting. The reason could be attributed to homogeneous coatings consisting of TiN and Ti-N-O phases. Therefore, the optimal heated coating could effectively improve the pitting corrosion of $316 \mathrm{~L}$ stainless steel in the study.

\section{CONCLUSIONS}

The TiN film arc-deposited on 316 L stainless steel after postheating at proper temperature could form a Ti-N-O outer-
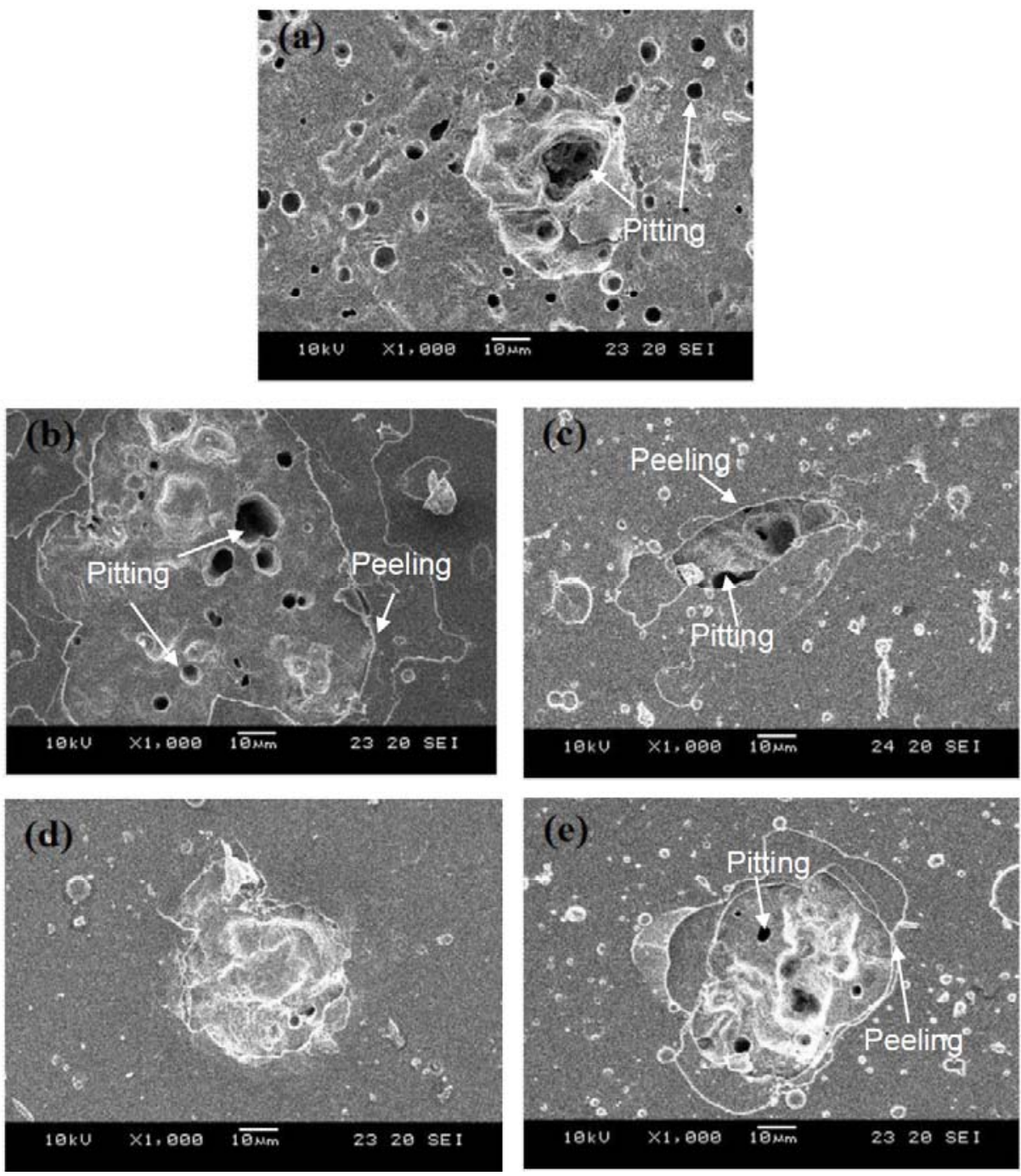

Figure 8: Surface morphology of the coated and uncoated specimens after 900 min immersion tests in 10 vol.\% $\mathrm{HCl}$ solution: (a) uncoated, (b) TiN, (c) TiN(400), (d) TiN (500), and (e) TiN(600). 
layer, consisting of rutile- $\mathrm{TiO}_{2}$ and $\mathrm{TiN}$ phases. The outerlayer in thickness had an increase with raising the postheating temperature. Moreover, the properties of the outerlayer such as composition, roughness, and adhesion were also dependent upon the heating temperature. When the heating temperature was controlled at $500{ }^{\circ} \mathrm{C}$, the formed outer-layer had the most uniform composition among all the heated coatings. Such a post-heated film could remarkably reinforce the pitting corrosion resistance of $316 \mathrm{~L}$ stainless steel.

\section{ACKNOWLEDGEMENTS}

The authors would like to thank the financial support of the National Science Council (Taiwan, ROC) under contract no. MOST 104-2221-E-036-001.

\section{REFERENCES}

[1] Smith WF. Structure and Properties of Engineering Alloys, McGrawHill Inc., New York, 1993, p.288.

[2] Lula RA. Stainless steel, ASM Ohio, 1986; p.150.

[3] Peckner D. Bernstein IM, Handbook of Stainless Steel, McGraw-Hill Inc., New York, 1977; p.15-1.

[4] Davison RM, DeBold T, Johnson MJ. Corrosion of Stainless Steels, Metals Handbook of ASM, 9th ed., 1980; Vol.13: p. 547.

[5] John Sedriks A. Corrosion of Stainless Steel, John Wiley \& Sons, Inc., New York, 1996; p.102.

[6] Budinski KG. Surface Engineering for Wear Resistance, Prentice-Hall Inc., New Jersey, 1988; p.138.

[7] Kok YN, Akid R, Hovsepian PEh. Tribocorrosion testing of stainless steel (SS) and PVD coated SS using a modified scanning reference electrode technique. Wear 2005; 259: 1472-81. http://dx.doi.org/10.1016/i.wear.2005.02.049

[8] Dearnley PA, Mallia B. The chemical wear (corrosion-wear) of novel $\mathrm{Cr}$ based hard coated $316 \mathrm{~L}$ austenitic stainless steels in aqueous saline solution. Wear 2013; 306: 263-75 http://dx.doi.org/10.1016/i.wear.2012.09.002

[9] Nose M, Zhou M, Honbo E, Yokota M, Saji S. Colorimetric properties of $\mathrm{ZrN}$ and TiN coatings prepared by DC reactive sputtering. Surface Coatings Technol 2001; 142-144: 211-7. http://dx.doi.org/10.1016/S0257-8972(01)01196-3
[10] Endrino JL, Fox-Rabinovich GS, Gey C. Hard AITiN, AICrN PVD coatings for machining of austenitic stainless steel. Surface Coatings Technol 2006; 200: 6840-5.

http://dx.doi.org/10.1016/i.surfcoat.2005.10.030

[11] Leoni M, Scardi P, Rossi S, Fedrizzi L, Massiani Y. (Ti,Cr)N and Ti/TiN PVD coatings on 304 stainless steel substrates: Texture and residual stress. Thin Solid Films 1999; 345: 263-9. http://dx.doi.org/10.1016/S0040-6090(98)01741-6

[12] Wallén $P$, Hogmark $S$. Influence of TiN coating on wear of high speed steel at elevated temperature. Wear 1989; 130: 123-35. http://dx.doi.org/10.1016/0043-1648(89)90227-5

[13] Chappé JM, Martin N, Lintymer J, Sthal F, Terwagne G, Takadoum J. Titanium oxynitride thin films sputter deposited by the reactive gas pulsing process. Appl Surface Sci 2007; 253: 5312-6. http://dx.doi.org/10.1016/i.apsusc.2006.12.004

[14] Vaz F, Cerqueira P, Rebouta L, et al. Preparation of magnetron sputtered TiNxOy thin films. Surface Coatings Technol 2003; 174 175: 197-203.

http://dx.doi.org/10.1016/S0257-8972(03)00416-X

[15] Hsu CH, Huang KH, Lin YH. Microstructure and wear performance of arc-deposited Ti-N-O coatings on AISI 304 stainless steel. Wear 2013; 306: 97-102.

http://dx.doi.org/10.1016/i.wear.2013.07.005

[16] Hsu CH, Huang KH, Lin MR. Annealing effect on tribological property of arc-deposited TiN film on $316 \mathrm{~L}$ austenitic stainless steel. Surface Coatings Technol 2014; 259: 167-71. http://dx.doi.org/10.1016/i.surfcoat.2014.02.001

[17] Heinke W, Leyland A, Matthews A, Berg G, Friedrich C, Broszeit E. Thin Solid Films 1995; 270: 431. http://dx.doi.org/10.1016/0040-6090(95)06934-8

[18] Uhlig HH. Corrosion and Corrosion Control, John Wiley \& Sons Inc. New York, 1971; p. 45.

[19] Jacob KS, Parameswaran G. Corrosion inhibition of mild steel in hydrochloric acid solution by Schiff base furoin thiosemicarbazone. Corrosion Sci 2010; 52: 224-8. http://dx.doi.org/10.1016/i.corsci.2009.09.007

[20] Hsu CH, Chen ML. Corrosion behavior of nickel alloyed and austempered ductile irons in $3.5 \%$ sodium chloride. Corrosion Sci 2010; 52: 2945-9.

http://dx.doi.org/10.1016/i.corsci.2010.05.006

[21] Pierson HO. Handbook of Refractory and Nitrides, Noyes Publications, New Jersey 1996; p.156. http://dx.doi.org/10.1016/B978-081551392-6.50010-6

[22] Hsu CH, Lee CC, Ho WY. Filter effects on the wear and corrosion behaviors of arc deposited (Ti, Al)N coatings for application on coldwork tool steel. Thin Solid Films 2008; 516: 4826-32. http://dx.doi.org/10.1016/.tsf.2007.09.017 